\title{
PSEUDOPREGNANCY IN A BITCH- A CASE REPORT
}

\author{
D. GARAI ${ }^{1}$, I. MUKHERJEE ${ }^{2}$, I. ROY ${ }^{3}$ AND A. MUKHOPADHYAY*4
}

${ }^{1}$ State Animal Health Centre, Chakdaha, Dist.-Nadia, Pin-741 222, West Bengal, India
2Division of Animal Physiology, NDRI, Karnal, Haryana, India
${ }^{3}$ Division of Animal Breeding, NDRI, Karnal, Haryana, India
${ }^{4}$ Tuberculosis and Brucellosis Control Unit, Chakdaha, Nadia, Pin-741 222, West Bengal, India

Pseudopregnancy is a common physiological phenomenon in bitch. A crossbred bitch was presented at State Animal Health Centre, Chakdaha, Nadia with the symptoms of pseudopregnancy. The bitch was treated with cabergoline and other supportive drugs. After 15 days of treatment all symptoms were gradually ceased and the bitch was fully recovered.

Key words: Bitch, Cabergoline, Pseudopregnancy

Pseudopregnancy, also known as false pregnancy, pseudocyesis or phantom pregnancy, is a common occurrence in female dog. It is a physiological phenomenon in the mammalian species specially in canine and feline, where all the signs and symptoms of pregnancy like nursing, ejection of milk from teat is observed inspite of the absence of foetus. In most of the literature both the terms, pseudopregnancy and false pregnancy are used interchangeably, although there are some differences. Pseudopregnancy is specifically referred to nonpregnant luteal phase of induced ovulators where progesterone level in serum is quite high. Whereas false pregnancy may be described as decline in serum progesterone level at the end of luteal phase (Razzaque et al., 2008). This article is actually based on observations which are similar to the later one. But we preferentially use the term pseudopregnancy throughout the later discussion to get rid of this confusion. Estimated incidence rate of pseudopregnancy may vary from $50 \%$ to $75 \%$ in most of the breeds of $\operatorname{dog}$ (Singh et al., 2018) though reported cases are scanty due to lack of diagnostic facilities in the field condition. In this context this paper mainly illustrates symptomatic diagnosis and treatment protocol of pseudopregnancy in a bitch which may help field veterinarians to handle such type of cases.

A crossbred (Spitz x Desi ?) bitch aged about 8 years having $20 \mathrm{~kg}$ body weight was presented at State Animal Health Centre, Chakdaha, Nadia, West Bengal with the symptoms of abdominal distension, enlargement of mammary glands as well as secretion of clear milk from teat on pressure, licking of mammary glands, loss of appetite and restlessness (Fig. 1). The owner of the bitch reported that the bitch carried cloths and other inanimate objects at the corner of house to form a nest. It was also reported that the bitch

\footnotetext{
"Corresponding Author
} 
Indian Journal of Animal Health, June, 2020

\section{Pseudopregnancy in a bitch}

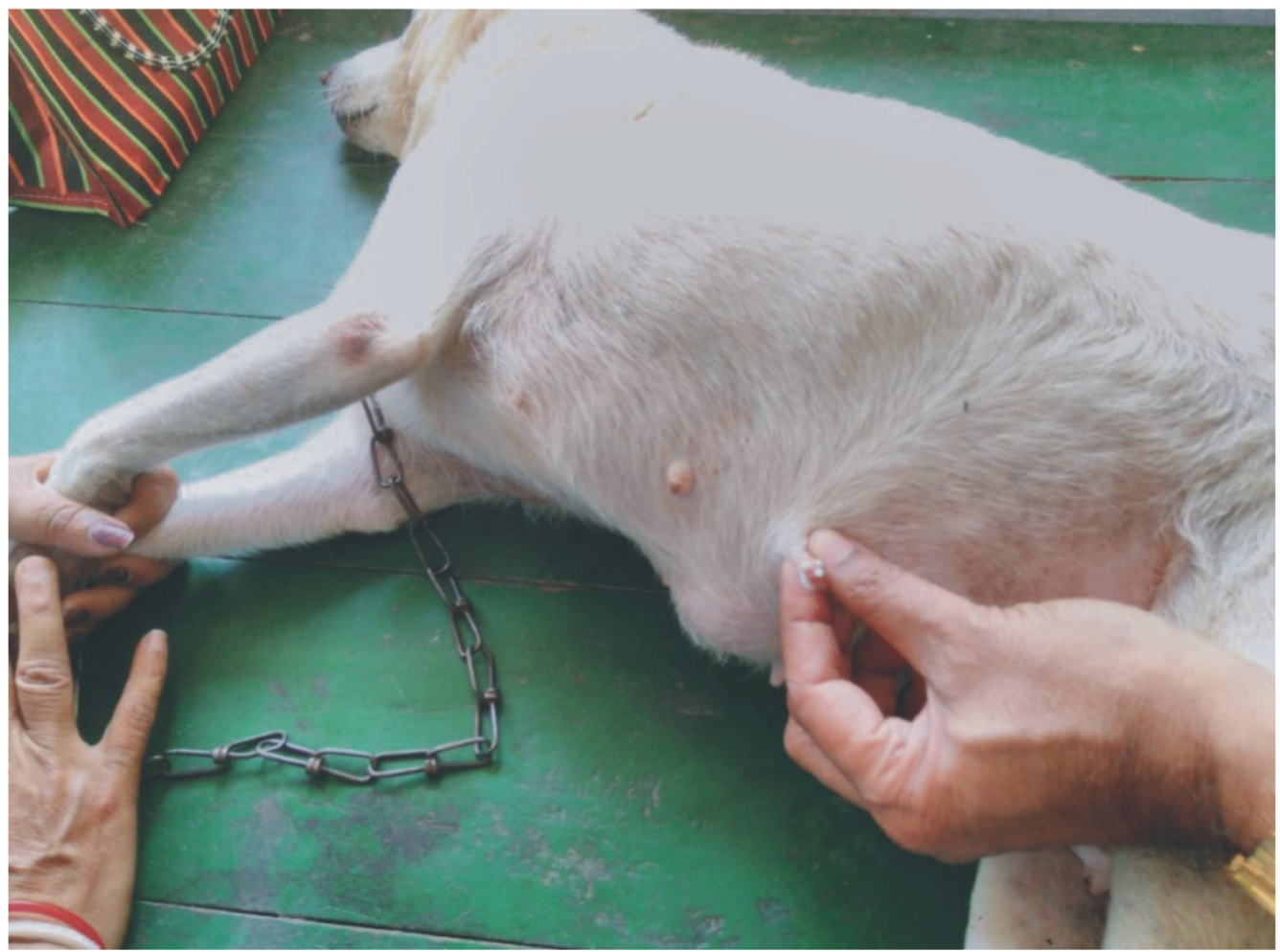

Fig. 1. Bitch showing symptoms of pseudopregnancy

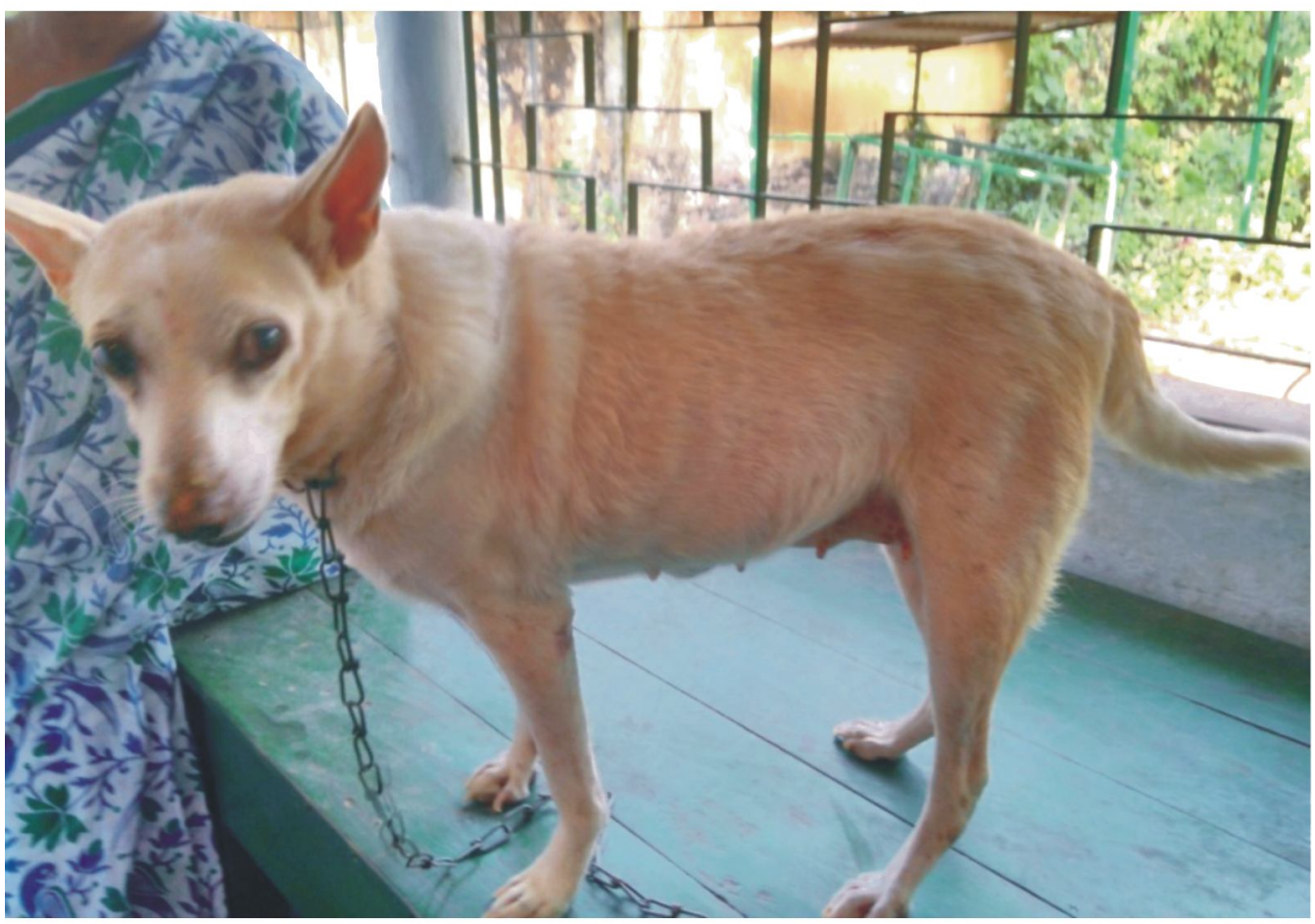

Fig. 2. Recovered bitch after 15 days of treatment 
became in estrous before 50 days but mating was not done. The bitch was kept in strict confinement in owner's residence; hence there was no possibility of accidental mating. On palpation of distended abdomen, foetal feeling was absent. As in the field condition radiographic and ultrasonographic facilities were not available, based on histories, symptoms and clinical examination the case was diagnosed as pseudopregnancy.

The bitch was treated with 1. cabergoline (Caberlin ${ }^{\circledR}-0.5 \mathrm{mg}$ tab)- $1 / 5^{\text {th }}$ tab per day for 7 days, 2. diazepam (Calmpose $\left.{ }^{\circledR}\right) 10 \mathrm{mg}$ tab per day for 5 days, 3. Liv-52 syrup- 2 t.s.f. b.d., a.c. for 15 days. After 15 days of treatment, mammary glands of bitch returned its normal size with no secretion of milk from teats and other symptoms of pseudopregnancy disappered (Fig. 2).

The actual physiological mechanism of pseudopregnancy is still not fully understood, but it is assumed that as the duration of metestrus, luteal or proestrus phase of the cycle is more or less same with the duration of pregnancy (8-9 weeks) in bitch, the characteristic signs of pregnancy are also observed in pseudopregnancy (Razzaque et al., 2008). Corpus luteum (CL) of non pregnant

\section{REFERENCES}

Concannon PW and Lein DH, 1989. Hormonal and clinical correlates of ovarian cycles, ovulation, pseudopregnancy and pregnancy in dogs. In: Kirk RW (edn.), Current Veterinary Therapy X. WB Saunders, Philadelphia. USA, pp1269-1282

Razzaque WAA, Husain K, Agarwal S and Kumar S, 2008. False pregnancy in bitches. Vet World, 1(3): 92-95

Sandhu HS, 2014. Essentials of Veterinary Pharmacology and Therapeutics, $2^{\text {nd }}$ edn., Kalyani Publishers, Ludhiana, India, pp347

Singh LK, Bhimte A, Pipelu W, Mishra GK and Patra MK, 2018. Canine pseudopregnancy and its bitches is regressed in around 45-60 days after the end of estrus. Due to the loss of CL, progesterone level declines gradually and the declining level of progesterone incites the release of prolactin which is the main responsible hormone for enlargement of mammary gland and lactation (Concannon and Lein, 1989; Tsutsui et al., 2007; Yenilmez and Eren, 2019).

The bitch was treated with cabergoline @5 $\mu \mathrm{g} /$ $\mathrm{kg}$ b.wt. (Sandhu, 2014) which is a dopamine-2 (D2) receptor agonist. This is an ergot derivative. Prolactin release from lactotroph is inhibited by dopamine (or its agonist) through the inhibition of adenylate cyclase enzyme by attaching with D2 receptor (Yenilmez and Eren, 2019). Diazepam, a non phenothiazine light tranquilizer drug was prescribed to treat changes of behavioural signs of the bitch as recommended by Singh et al. (2018). Liv-52, a liver tonic was used for restore normal appetite.

The bitch showing the symptoms of pseudopregnancy was successfully treated with the drug cabergoline and other supportive therapies. But ovariohysterectomy may be performed for permanent solution of pseudopregnancy in non-breeding bitches (Thangamani et al., 2018).

treatment strategies. J Entomol Zool Stud, 6(3): 1076-1078

Thangamani A, Srinivas M, Chandra Prasad B, Anusha K and Sadasiva RK, 2018. Canine pseudopregnancy: A review. J Vet Sci Tech, 7(1): 7-11

Tsutsui T, Kirihara N, Hori T and Concannon PW, 2007. Plasma progesterone and prolactin concentrations in overtly pseudopregnant bitches: A clinical study. Theriogenology, 67(5): 1032-1038

Yenilmez K and Eren N, 2019. The utilization areas of cabergoline in veterinary gynecology. J Res Vet Med, 38(1): 77-81

Received-09.04.2020, Accepted-13.05.2020, Published-01.06.2020 